\title{
Ecos de la historia rumana en la literatura: las mira- das de Mircea Eliade y Mircea Cărtărescu
}

\author{
Alba Diz VillanueVA \\ Departamento de Filología Románica, Fil. Eslava y Lingüística General \\ Universidad Complutense de Madrid \\ albadiz@ucm.es
}

\section{RESUMEN}

La novela Noaptea de Sânziene, de Mircea Eliade, y las tres que conforman la trilogía Orbitor (Aripa stângă, Corpul y Aripa dreaptă), de Mircea Cărtărescu, recrean, desde diferentes puntos de vista, algunos de los acontecimientos más importantes de la historia rumana del siglo XX. El objetivo de este artículo es analizar, desde una perspectiva comparatista, el tratamiento ficcional del material histórico por parte de ambos autores.

Palabras clave: Mircea Eliade, Mircea Cărtărescu, Rumanía, Historia.

[Recibido, diciembre 2014; aprobado, marzo 2015]

Echoes of Romanian History in Literature: Mircea Eliade and Mircea Cărtărescu's visions

\begin{abstract}
Mircea Eliade's Noaptea de Sânziene and Mircea Cărtărescu's trilogy Orbitor (Aripa stângă, Corpul and Aripa dreaptă) rewrite some of the most important events of the 20th Century History of Romania. The aim of this paper is to analyze, from a comparative perspective, these novel's fictional treatment.
\end{abstract}

Keywords: Mircea Eliade, Mircea Cărtărescu, Romania, History. 


\section{Introducción}

El 4 de abril de 1944, las alarmas antiaéreas suenan en la capital rumana. Muchos habitantes corren a los refugios dispuestos por la ciudad; para otros, que habían creído que se trataba de un nuevo simulacro, es tarde cuando los aviones americanos cubren ya el cielo. Durante varias horas, y en los días y meses posteriores, fuerzas aéreas de la coalición angloestadounidense bombardean Bucarest y otras poblaciones cercanas ${ }^{1}$, causando miles de víctimas y múltiples daños materiales tanto en el patrimonio arquitectónico como en algunas de las principales infraestructuras urbanas. La estación de ferrocarriles (Gara de Nord), las vías y los talleres colindantes, numerosas biserici y algunos de los edificios más emblemáticos de la geografía bucarestina -como el Teatro Nacional y los hoteles Splendid o Athénée Palace en Calea Victoriei, una de sus principales arterias- resultan devastados. En este balance funesto se dejan sentir las más graves consecuencias hasta el momento, dentro de las fronteras nacionales, de la implicación en la Segunda Guerra Mundial de Rumanía, que, tras mantenerse neutral durante los primeros años del conflicto, entra en 1941 del lado del Eje, en aras de recuperar los territorios perdidos en favor de la URSS, Hungría y Bulgaria.

Los bombardeos de los Aliados sobre Bucarest son recreados, desde ópticas bien distintas y con una diferencia temporal de cuatro décadas, en dos novelas que constituyen verdaderos hitos en la narrativa rumana del siglo XX: Noaptea de Sânziene (La noche de San Juan) (1955), de Mircea Eliade, y Orbitor. Aripa stângă (Cegador) (1996), de Mircea Cărtărescu. Como cabe esperar de unos hechos de tal magnitud, este episodio supone, desde la perspectiva del entramado narrativo y el desarrollo de los personajes, un punto de inflexión en ambas novelas, como lo fue también en el propio devenir histórico de Rumanía.

Las obras analizadas consignan estos acontecimientos como el primero de una larga serie de infortunios por la que atravesará el país en los años posteriores al armisticio. Se enmarcan, pues, en un contexto más amplio, previo y/o ulterior. Mientras que La noche de San Juan, cuya acción transcurre entre 1936 y 1948, sigue de cerca la gestación, desarrollo y repercusiones más inmediatas de la guerra, que inciden de forma directa en la vida de los personajes, en la segunda las referencias bélicas se limitan casi exclusivamente a la recreación de los bombardeos y se encuadran en la reconstrucción del pasado de la madre del protagonista, en el que tendrán, sin embargo, una gran relevancia.

\section{Eliade ante la historia}

La noche de San Juan nos sitúa, en su comienzo, en el solsticio de verano de 1936, en una ciudad de Bucarest todavía en relativa calma, pero inquieta ante las noticias y los rumores que llegan desde otros puntos de Europa. Esta creciente agitación, motivada por los profundos cambios del escenario europeo (la Guerra Civil española, el rearme de Hitler y su expansión territorial...) y las transformaciones que comienzan a operarse también dentro de las propias fronteras (la disolución del Parlamento y la instauración de la dictadura del rey

\footnotetext{
${ }^{1}$ Una de las ciudades más afectadas es Ploești, situada a poco más de 50 kilómetros de Bucarest, que, por albergar las principales refinerías del país, con las que proveía de petróleo y de sus derivados al Eje, constituyó un objetivo estratégico de los ataques de la aviación anglo-norteamericana desde junio de 1942 y, sobre todo, entre agosto de 1943 y el verano de 1944.
} 
Carol II, el auge del movimiento legionario, el cada vez más palmario antisemitismo...), no logra sin embargo que el protagonista, Ștefan Viziru, ceje en su empeño por transcender el tiempo, por buscar señales de una posible salida hacia un estado extrahistórico, atemporal, como aquel que encontrara en la habitación secreta Sambo, "un lugar paradisiaco", existente "en la tierra, junto a nosotros, al alcance de la mano y, no obstante, invisible a los demás, inaccesible a los no iniciados, un espacio privilegiado" (Eliade 2001: 90).

Su rechazo del tiempo histórico ${ }^{2}$ lleva a Ștefan Viziru a ignorar el peligro que se cierne ya sobre el continente. Su pasividad contrasta con la preocupación generalizada de la sociedad rumana, así como de su entorno más cercano, que permanece atento al curso de la Alemania del Führer, cuyo triunfo concibe como muerte espiritual, y previsiblemente también física, de Europa. Son muchos los amigos y compañeros que advierten al protagonista, absorto en sus ensoñaciones y pensamientos, de la inmediatez de la guerra y el advenimiento de una nueva coyuntura que de antemano se sabe catastrófica "El gran incendio se aproxima, ¡créeme! Nos vamos a quedar reducidos a polvo y ceniza. [...] Ahora es el momento de ponerte a resguardo. Y rápido [...] ¡Los acontecimientos están a la vuelta de la esquina y te barrerán!” (Eliade 2001: 138-139). Al avance del fascismo en terreno internacional y el terror que ello provoca, se suma el de su vertiente nacional, la Guardia de Hierro, dirigida por Corneliu Codreanu, que logra un crecimiento exponencial de los votos recibidos en las elecciones de 1937, gracias a los apoyos de intelectuales, estudiantes, sacerdotes y una parte del campesinado (Stefanescu 2004: 8). Los intentos del nuevo régimen por reprimir el avance de los legionarios generan un clima turbulento en que los registros policiales, las persecuciones, las infiltraciones en las principales instituciones y los informantes, los interrogatorios y las detenciones están a la orden del día. Las leyes se modifican para endurecer el control sobre una población que deviene sospechosa de colaborar con el movimiento. Como expone Biriş, amigo de Viziru, tamaña restricción de las libertades civiles equipara al gobierno y los métodos empleados con los fascistas, cuyas consecuencias recaen no solo sobre legionarios, sino sobre todos los ciudadanos.

$\mathrm{Ni}$ todas las advertencias ni el panorama ostensiblemente convulso, fruto de las luchas internas por el poder y del conflicto europeo, consiguen hacer consciente al protagonista de la seriedad de las circunstancias. Estas, hasta entonces ajenas, irán no obstante afectándole de forma cada vez más directa y severa: es detenido por alojar a un simpatizante de la Guardia de Hierro (vulnerando además la reciente ley que prohíbe alquilar una vivienda o acoger en ella a alguien sin informar antes a la policía) y, tras varios días incomunicado en la prefectura, es internado en un campo de concentración de legionarios en Miercurea Ciucului $^{3}$, donde permanece durante unos meses, junto a otros 300 presos, en su mayoría intelectuales del movimiento. Aunque es informado de que ha sido destituido del Ministerio, por lo que las probabilidades de que alguien acuda en su ayuda o aclare la confusión son

\footnotetext{
${ }^{2}$ Ante el «terror a la historia»-que consiste, según García García (2007: 54), en el temor a la pérdida de la memoria, a la pérdida del pasado que impone el paso del tiempo-, el protagonista opta, de entre las dos posibilidades de defensa existentes, la acción y la contemplación (Eliade 2001: 263), por la segunda.

${ }^{3}$ El internamiento de Viziru en Miercurea Ciucului es de inspiración autobiográfica. Mircea Eliade fue recluido allí, por su relación con la Guardia de Hierro y con su ideólogo y a la vez mentor de Eliade (Biliuță 2007), Nae Ionescu, entre abril de 1938 y el 25 de octubre de ese mismo año, cuando es trasladado al sanatorio de Moroeni, que abandonará tres semanas más tarde (Mutti 2005: 26).
} 
mínimas, Ștefan se niega a firmar una declaración que, si bien lo libraría de la reclusión, implicaría reconocer su culpabilidad. Allí, a Viziru y al resto de internos se les comunicará, durante la noche de San Andrés (30 de noviembre de 1938), la muerte del capitán de los legionarios y miembro fundador de la Guardia de Hierro, Codreanu, asesinado por orden del monarca. Este hecho desencadenará una ola de violencia que traerá, entre otras consecuencias, el magnicidio del primer ministro, Armand Călinescu, el 21 de septiembre de 1939, y, como represalia, el asesinato de cientos de legionarios en todo el país y la exposición pública de sus cuerpos. Ștefan, ya en libertad, resulta indemne, pero su suerte pronto habrá de cambiar. Cuando vuelve del lagar, sabe de la muerte de Partenie, su doble, asesinado por la policía, al encontrarse en compañía de un legionario que lo confunde con Viziru, lo cual lleva a este último a afirmar: "Lo han matado por mi causa [...]. Lo confundieron conmigo. En cierto sentido, lo he matado yo" (Eliade 2001: 204).

El panorama se agrava. Polonia es invadida y la guerra estalla. Rumanía mantiene una frágil neutralidad que amenaza con romperse ante la hostilidad de los países circundantes. Diariamente recibe refugiados polacos y la posibilidad de una ocupación alemana preocupa a muchos rumanos. Desde el frente oriental avanzan los soviéticos, que exigen la cesión de Besarabia y el norte de Bucovina, regiones que, de acuerdo al pacto Ribbentrop-Mólotov firmado en agosto de 1939, se situaban en el área de interés de la URSS (Giurescu 1999). La situación estratégica de Rumanía, que cuenta con un río navegable que recorre buena parte de su geografía, como es el Danubio, y con salida hacia el Mar Negro, sumada a la repartición territorial derivada de la Gran Guerra, hacen de ella un objetivo de algunas de las principales potencias implicadas en el conflicto bélico. Asfixiada entre dos frentes, las consecuencias de la contienda no se hacen esperar: a las pérdidas de los territorios nororientales se suman la anexión del norte de Transilvania por Hungría y la de la Dobruja meriodional por Bulgaria (Arbitraje de Viena y Acuerdos de Craiova, respectivamente), que pondrán fin al Reino de la Gran Rumanía ${ }^{4}$.

En estas circunstancias, en 1940, Ștefan es enviado en misión diplomática a la capital inglesa, donde consigue sobrevivir a los ataques de la Luftwaffe -que dejan una ciudad convaleciente y mermada en población- guareciéndose en los refugios y en el metro, así como, una vez más, en sus propios recuerdos, que se intercalan constantemente en el relato de la acción principal. Tras la batalla de Londres, aumenta la desconfianza hacia los extranjeros y en especial hacia los rumanos, que, como le había prevenido el ministro, son sospechosos de espionaje. Por ello, encontrará problemas para abandonar el país ${ }^{5}$. Pero ya durante el desarrollo del Blitz, Viziru y sus compatriotas Vădastra y Antim tratan de permanecer callados, a pesar de los sobresaltos por los cañonazos de la artillería antiaérea y las bombas que dejan caer "las palomas de Hitler" (Eliade 2001: 269), para que el resto de las personas del refugio no descubran su procedencia.

Durante su estancia en el extranjero (a Londres le sucederá Lisboa), recibe noticias de

\footnotetext{
${ }^{4}$ En total, entre el 28 de junio y 7 de septiembre de 1940, Rumanía pierde casi 100.000 km² y más de 6.800 .000 de habitantes. Las pérdidas representan un 33,79\% del territorio y el 34,02\% de la población (Giurescu 1999: 33).

${ }^{5}$ En su Diario portugués, Eliade refiere un episodio similar. Al intentar abandonar Inglaterra, después de los bombardeos de Londres y otras ciudades, en el aeropuerto le comunican que ya no consta entre los miembros de la legación diplomática, es sometido a un minucioso cacheo corporal y se le requisa la valija, igual que le sucede a Viziru (Eliade 2001b: 202-203).
} 
los últimos acontecimientos que sacuden Rumanía: la Guardia de Hierro se ha sublevado contra el general Antonescu, la rebelión se ha extendido por todo el país y el ejército lucha para intentar contener a los legionarios. El terror y el caos se apoderan de las calles, donde se apilan los muertos, los judíos son "perseguidos como fueras feroces, degollados y descuartizados como reses en el matadero" (Eliade 2001: 291) y los saqueos, los asesinatos y el pillaje se suceden por doquier. La insurrección es sofocada, pero el caos no cesa, pues es el turno de las represalias: detenciones en masa, juicios sumarios, redadas, registros...

El 22 de junio de 1941 Rumanía entra oficialmente en la guerra junto a Alemania y sus aliados, con el objetivo de recuperar los territorios perdidos. Meses después, el protagonista, en una suerte de tentativa suicida, se alistará voluntariamente para combatir en el frente y contener el avance de las tropas rusas. Refugiado hasta entonces en el recuerdo o en la imaginación, como en una suerte de eje espacio-temporal paralelo que le permite sobrellevar la realidad, participa ahora de ella, viviendo de primera mano el transcurso de los acontecimientos, el desarrollo de una contienda dura y cruenta, con implicaciones morales y éticas que evidencian la descomposición a que esta conduce. La guerra amenaza al individuo, cuya integridad física y mental es susceptible de ser aniquilada en cualquier momento, sin que ello tenga la menor trascendencia, y trunca el funcionamiento del conjunto de la sociedad, que queda sujeta a sus designios:

\begin{abstract}
Nuestro amo, el de todos, es hoy la guerra [...]. Ella ha confiscado toda la historia contemporánea, el tiempo en el que el destino dispuso que tendríamos que vivir. Toda Europa está viviendo como un autómata monstruoso, al que ponen en movimiento las noticias que cada minuto difunden las emisoras de radio, las ediciones especiales de los periódicos, las conversaciones entre amigos, etc. Incluso cuando nos quedamos solos, siempre estamos pensando en la guerra, es decir, que seguimos siendo esclavos de la Historia. El terror de los acontecimientos es no sólo humillante para cada uno de nosotros como seres humanos sino que es, a la postre, estéril (Eliade 2001: 262).
\end{abstract}

Los intentos de abstraerse de la historia resultan del todo infructuosos cuando esta evidencia su fuerza destructora, que se materializa en las vivencias de Viziru en el frente, pero, sobre todo, en los bombardeos del 4 de abril de 1944, que reducen su casa a escombros y acaban con la vida de su mujer y su hijo. El panorama es desolador: aviones de la USAAF oscurecen el hasta entonces límpido cielo y lanzan sus bombas sobre Bucarest, dejando a los supervivientes desconcertados, entre cadáveres, columnas de humo, edificios desmoronados o incendiados, cráteres en el suelo y aceras llenas de escombros y hollín. Ștefan, recién llegado a la ciudad tras haber sido evacuado de Crimea, descubre con desesperación la suerte de su familia, atrapada en el interior del antiguo hogar-que es ahora sepultura-, en el siguiente fragmento, narrado desde la perspectiva del personaje de Irina:

De pronto, al llegar a la esquina lo comprendió todo. En el lugar donde antes estaba la casa de Ioana, al igual que otras muchas de alrededor, ahora había varias montañas humeantes de cascotes y escombros que llegaban hasta la mitad de la calle. Grupos de personas subían y bajaban entre las ruinas tambaleándose, cegados por el polvo, tropezando con las vigas, gritando como locos y tapándose enseguida la boca con la mano y levantando intermitentemente sus brazos ensangrentados al cielo $[\ldots]$.

[...]. Lo vio acercarse. Stefan intentó llevarse la mano a la frente pero desistió y se quedó con la palma vierta muy cerca de la cabeza, sin saber qué hacer hasta que el brazo empezó a temblarle y entonces lo dejó caer con un gesto de impotencia. Un instante después, lo vio correr hacia las ruinas, tropezar y caer. Pero se levantó inmediatamente y siguió corriendo, trepando por los montículos de escombros, llegaba hasta arriba y se volvía a caer, seguía arrastrándose de rodillas escarbando con las 
dos manos entre los cascotes hasta que un soldado que había subido detrás de él lo agarró por la cintura y lo arrastró hasta la calle (Eliade 2001: 381-382).

La tensión entre la dramática realidad histórica y la voluntad de trascenderla a otra superior y distinta (Carmona Fernández 2010: 24) en que vivía el protagonista se resuelve a favor de la primera: aquello a lo que hasta entonces había dado la espalda, el cada vez más aciago devenir de los acontecimientos y sus propios recuerdos, que no hacen sino acrecentar el dolor, se tornan omnipresentes e ineludibles. Como le dice su amigo Biriș, la Historia, con mayúscula, ha borrado su historia, destruyendo a su familia, su hogar y todas las huellas palpables de su pasado que este contenía.

El transcurso del enfrentamiento bélico, que en un principio se preveía, erróneamente, corto y victorioso para los alemanes, permite a los personajes anticiparse a los hechos. El avance del Ejército Rojo, su entrada en Moldavia y, sobre todo, la caída de Stalingrado en el invierno del 43 llevan al protagonista a asegurar: «Hemos perdido la guerra. Dentro de un año o dos, los rusos estarán aquí, los tendremos encima de nosotros, en Bucarest...» (Eliade 2001: 368). Esta aseveración deviene augurio pues, efectivamente, un año y medio después, tras el golpe de Estado del rey Mihai (23/08/1944), se anuncia el cese de las hostilidades con los rusos, los nuevos aliados que acuden para liberar al país del peligro de una nueva ocupación alemana. El 31 de agosto las tropas soviéticas entran en Bucarest. Pese a la creencia de algunos en su pronta retirada y en la caída del gobierno de Petru Groza impuesto por Vîșinski, sea por el armisticio, sea por la presión y el poderío de EE.UU., que no podría permitir el dominio ruso en los Balcanes, otros enseguida comprenden la situación y tratan de adaptarse a los nuevos tiempos y a los nuevos dirigentes, como Bibicescu, rápidamente afiliado al $\mathrm{PCR}^{6}$, quien

[...] no necesitó mucho tiempo para darse cuenta de que los rusos iban a ser los auténticos amos. [...] Había visto cómo unas decenas de comunistas armados, transportados en camiones soviéticos, sembraban el terror en los sindicatos de las fábricas y en las reuniones de los otros partidos sin que nunca les pasara nada. Las divisiones rumanas estaban luchando lejos, en Hungría y en Checoslovaquia, al lado de los rusos y contra los alemanes. Las ponían siempre en primera línea y los hombres caían como moscas. A pesar del armisticio, todas las tropas que se encontraban en el frente de Moldavia fueron capturadas y enviadas a Rusia. En Rumania casi no había unidades armadas. Poco a poco, la gendarmería, la policía y los servicios de la Seguridad pasaron a manos de los comunistas (Eliade 2001: 419).

La novela de Mircea Eliade retrata los primeros años de la posguerra y la ocupación soviética, marcados por los abusos y desmanes de los soldados rusos, tales como robos,

\footnotetext{
${ }^{6}$ Como señala Deletant (2006: 49-51), el golpe de Estado tuvo un impacto crucial sobre el Partido Comunista Rumano, que todavía a comienzos de 1944, tras 23 años de existencia, era una pequeña agrupación política, formada por distintas facciones, con una repercusión efectiva reducida. En otoño era ya un factor influyente en la escena política y a finales de año estaba en el primer plano de los acontecimientos, gracias al poder del ocupante soviético. El PCR pronto borrará las rivalidades faccionarias ante la necesidad de asumir el rol que Stalin le había otorgado en el futuro de Rumanía y tomará una serie de medidas para "reeducar" al país en un estado de obediencia frente a la Unión Soviética. En 1947, el PCR, tras su fusión con otros partidos y tras el desmantelamiento de las principales fuerzas opositoras, devendrá partido único de masas, bajo la denominación de Partid Muncitoresc Român (Partido Obrero Rumano) (2006: 85-87).
} 
expropiaciones y expoliaciones, violaciones o agresiones contra los ciudadanos, así como por la represión institucional y férreos mecanismos de control, que pasan por el espionaje, las detenciones, las torturas, las deportaciones y los asesinatos. Algunos personajes sufren de forma directa estos excesos, como Cătălina, violada en un portal por un soldado soviético borracho; como la familia de Ileana, cuya casa señorial es saqueada y quemada, previa repartición de los terrenos; como Biriș, encerrado y torturado hasta la muerte ante las sospechas de pertenecer a la resistencia. En boca de este último personaje se denuncia la condición de moneda de cambio de Rumanía tras los acuerdos de paz y el abandono por parte de las potencias occidentales ${ }^{7}$, que deja al país a expensas de Moscú. Ante tal coyuntura, la única forma que el ocupado tiene de sobrevivir es el camuflaje, la máscara, la aceptación fingida de un enemigo contra el que es inútil combatir, lo que a la postre podría derivar en algo si cabe peor que la aniquilación física: la pérdida del alma.

Ștefan, como muchos otros rumanos y el propio Eliade, encuentra la salida a esa «nueva Era tenebrosa» (Eliade 2001: 527) en el exilio. Aunque con el objetivo principal de reencontrase con Ileana -por quien siente, desde la tarde de junio del 36 en que la conoce en el bosque de Baneasa, un amor casi obsesivo-, huye a París llevando consigo importantes documentos secretos comprometedores para el gobierno, relativos a las deudas de guerra y a acuerdos económicos con los rusos. Esta opción, sin embargo, se frustra en el caso de Biriş, a quien tienden una trampa en su intento de cruzar la frontera con Hungría desde Arad y a quien tratan de involucrar en una red de fuga y resistencia en los Cárpatos, a pesar de que ni cree en la resistencia ni la ejercita, llegando a hacer una confesión falsa, inventada, que no lo librará de la muerte.

\section{Cărtărescu y la reescritura del pasado}

La trilogía Orbitor de Cărtărescu retoma la etapa comunista unos solo unos años después del punto en que la deja la novela de Eliade, escrita entre 1949 y 1954 y cuya acción concluye como hemos dicho en 1948. El protagonista de Orbitor es Mircea, trasunto del escritor y nacido, como él, en $1956^{8}$. Su infancia y su adolescencia, sobre las que vuelve constantemente a través de la escritura de su manuscrito, transcurren, por tanto, durante el gobierno de Gheorghiu-Dej y los primeros años del de Ceaușescu, que se extiende hasta el presente del relato, bien entrada la década de los 80 , y terminará, como el propio manuscrito, en el fatídico año de 1989. Pero en su reconstrucción del pasado, Mircea se retrotrae a la juventud de su madre, lo que permite también una visión, aunque menos extensa, del Bucarest en guerra, sacudido por los bombarderos estadounidenses, e inmediatamente anterior, cuando Maria comenzaba su andadura en la urbe tras dejar su pueblo natal, y también del Bucarest

\footnotetext{
${ }^{7}$ Onişoru (1998: 132) señala que, tras los acontecimientos de 1944, las esperanzas de la población rumana estaban puestas en las democracias occidentales, en primer lugar EE.UU., cuyos líderes habían anunciado en varias ocasiones que con la paz los pueblos conquistarían de nuevo su libertad.

${ }^{8}$ Nótese que al contrario de Eliade, quien conoció de cerca, como atestiguan sus diarios, los prolegómenos, el desarrollo y las repercusiones de la guerra, Cărtărescu nace más de una década después de la finalización del conflicto. Esto tiene consecuencias evidentes en sus textos: en el del primero es un tema central, mientras que en los del segundo la Segunda Guerra Mundial actúa como un marco que da pie a la inclusión de una serie limitada de acontecimientos $-\mathrm{y}$, como tal, es útil desde el punto de vista literario- y a la introducción de una época que sí conoció y sufrió, y que es recreada con mucho más detalle, a saber, la comunista.
} 
custodiado todavía por soldados soviéticos a mediados de la década de 1950, cuando las calles del centro, ahora grises y hurañas, exhiben los nuevos símbolos: banderas rojas, estrellas de cinco puntas, hoces y martillos, estatuas de líderes comunistas, carteles de películas y rótulos de cinematográficos y demás establecimientos con clara intención ideológica, que ensalzan la democracia popular, la paz, el trabajo o la fraternidad entre los pueblos.

La recreación que de los bombardeos realiza Cărtărescu se focaliza, como la de Eliade, en una zona concreta de la capital, donde se sitúa la vivienda de un personaje principal del relato, en este caso la céntrica calle de Pictor Arthur Verona, en la que vive y trabaja Maria. La devastación de este espacio, al igual que la de la casa de Ștefan y el entorno circundante en La noche de San Juan, es total. Los efectos de las bombas se definen como una auténtica «carnicería» (Cărtărescu 2010: 182), subrayando el exterminio físico de los habitantes y de la propia ciudad. Los cuerpos humanos y urbano resultan destrozados, de forma tal que sus miembros cercenados se entremezclan: el polvo se impregna de la sangre de las víctimas, entre las grietas de los edificios asoman huesos y vísceras, órganos intactos relucen sobre lo que queda del adoquinado... Conforme avanzan por tal escenario, Maria y su hermana reconocen en ese cementerio en que se ha convertido la calle donde transcurría su vida bucarestina, como si de un museo se tratara, las historias y los secretos de sus habitantes, que la muerte exhibe a los ojos de las muchachas sin ningún pudor:

\begin{abstract}
¿Quién habría podido pensar que Gavrilescu, aquel fotógrafo barrigón y un poco bobo [...] y que ahora yacía ensangrentado sobre un montón de fotos de niñas desnudas, era un espía astuto y competente? Porque Măria y Vasilisca, al pasar por delante de lo que había sido el gabinete fotográfico, estaban pisando inestimables fotos aéreas de bases alemanas [...]. O el viejo Titi [...], que yacía ahora en medio de un cúmulo de conchas dispersas por todas partes [...], demostrando haber sido en materia de conchas de gasterópodos uno de los coleccionistas más grandes y raros, no más de un centenar en todo el mundo. Pero yacía allí tumbado boca arriba, despanzurrado, como una preparación anatómica, como un ratón descolorido en un frasco de alcohol, exponiendo su hígado, su corazón y sus pulmones, el intestino grueso y el intestino delgado, los riñones y la vejiga (Cărtărescu 2010: 183-184).
\end{abstract}

Si en La noche de San Juan la guerra, con los bombardeos que traen la muerte y la destrucción a la ciudad, impone brutalmente una realidad que hasta entonces el protagonista había querido ignorar, en Orbitor determinará un cambio importante en la relación de la joven Maria con el espacio urbano, que estará marcada, a partir de este momento, por el miedo y el confinamiento en la vivienda familiar: tras abandonar temporalmente Bucarest para refugiarse en Tântava de los convulsos acontecimientos derivados del conflicto bélico, regresará y descubrirá una nueva cara de la ciudad con visos de irrealidad o fantasía, próxima a lo onírico y alucinatorio.

Cuando recorre, doce años después ${ }^{9}$, su antigua calle encuentra, junto a nuevos edificios que sustituyen a los destruidos por el ataque aéreo, lo único que sobrevivió: la caja del ascensor con enrejado de metal de una de las construcciones bombardeadas. En este escenario del horror, como más delante en otros espacios subterráneos que se abrirán solo ante

\footnotetext{
${ }^{9}$ Es, concretamente, en 1955. Los bombardeos recreados en Orbitor se sitúan, por tanto, en 1943, un año antes del gran bombardeo del 4 de abril de 1944, que Eliade reescribe respetando la cronología histórica y que inspiraron también el relato cărtăresciano.
} 
Maria (y ante otros personajes cercanos a ella), comenzará a tomar conciencia de un destino que la asusta tanto o más que el episodio allí vivido: en claro paralelismo con la Anunciación bíblica, la ascensorista, encerrada en su particular cárcel desde la catástrofe, le hará saber que es la elegida para, como averiguará después, dar a luz a Mircea, el escritordemiurgo que los habrá de crear a todos en su relato.

La misma guerra que impone la Historia y aleja a Viziru de su obsesiva búsqueda de la Salida, de cuya evidencia tuvo constancia con el hallazgo de la habitación Sambo, para Maria supone el comienzo de un camino -simbólico, pero también literal, a través de la calle de la muerte y de criptas infinitas- hacia el conocimiento, la revelación del sentido de su propia existencia. En cierta medida, la ansiada Salida de la novela de Eliade es análoga a esas entradas al Bucarest posbélico y subterráneo presentes en Orbitor: como aquella, estas son accesibles tan solo para los iniciados y penetrar en ellas supone la anulación del tiempo.

Lo que en La noche de San Juan se presenta como futuro negro de Rumanía se confirma en las novelas cărtărescianas como un tiempo de penurias y de coartación de los derechos y las libertades de los rumanos por parte del Estado, que pone en funcionamiento todos los mecanismos represores para ejercer un fuerte control sobre la población. Eliade sitúa el foco en el desarrollo y las consecuencias más tempranas de la guerra en el país, mientras que Cărtărescu recrea con bastante profusión, aunque también con múltiples evasiones hacia lo onírico-fantástico, los efectos que ello tendrá durante las décadas posteriores. Aunque el tratamiento de la materia histórica es indudablemente paródico e irónico respecto del relato oficial $^{10}$, y está sujeto a sus intenciones narrativas, que transgreden su veracidad en no pocas ocasiones, lo cierto es que la Rumanía comunista aparece retratada de un modo bastante fiel, que permite al lector aprehender el ambiente de la época, a través de la familia protagonista -obreros a los que el régimen permite en un principio mejorar sus condiciones socioeconómicas, posibilitando el acceso a un empleo y una vivienda mejores, pero a los que acabará decepcionando y constriñendo, como al grueso de la sociedad-, pero también gracias a otros personajes heterogéneos, que van desde un agente del servicio secreto (Securitatea) que sufrirá en sus carnes torturas y técnicas de interrogatorio más que cuestionables, a una activista dispuesta a todo por escalar posiciones en la jerarquía del Partido Comunista.

Ya antes del regreso de Maria a la capital, en el pequeño pueblo de Tântava, se hace notar la llegada del nuevo invasor, ante el que los soldados alemanes a los que hasta el verano de 1944 se podía ver en los hoteles, los cafés, las tiendas o recorriendo las calles de las principales ciudades del país en elegantes coches negros, parecen un mal menor. Los robos, violaciones o asesinatos cometidos por los soviéticos, así como las temidas y violentas colectivizaciones que afectan al rural, hacen incluso extrañar al ocupante alemán, educado y trabajador en opinión de algunos aldeanos.

Las implicaciones de la vida tras el Telón de Acero se dejan sentir, de una u otra manera, en el día a día de la población, que, con algunos momentos de relativa calma e incluso de entusiasmo ante la esperanza de cambios en el país ${ }^{11}$, debe lidiar con cortes frecuentes en el

\footnotetext{
${ }^{10}$ Críticos como Ciobanu (2002) o Cernat (2007) han señalado el carácter posmoderno de la deconstrucción irónica del mundo comunista que realiza Cărtărescu en su trilogía, de los procedimientos empleados para revisitar la reciente historia autóctona y caricaturizarla.

${ }^{11}$ Dos de esos momentos significativos son la llegada al poder en 1967 de Nicolae Ceaușescu, que prometía una cierta apertura, una liberación respecto de las directrices procedentes de Moscú y el viraje hacia Occidente, y su
} 
suministro eléctrico, con el hambre y la escasez generalizadas, con las cartillas de racionamiento y las interminables colas para la conseguir alimentos y otros productos de primera necesidad, sometidos además a una vigilancia y un control constantes, que se ejercen no solo a través de los órganos de «seguridad», sino también de los medios de comunicación, del sistema educativo, de los comités empresariales o de los propios ciudadanos (entre los que se promueve y recompensa la delación). Estas se manifiestan tanto en el ámbito público como en el privado, en virtud a leyes que penetran en la intimidad de los rumanos y la vulneran profundamente. Un claro ejemplo de ello son las políticas de planificación familiar y crecimiento de la natalidad, que tienen nefastas consecuencias: abortos clandestinos que derivan muchas veces en muerte, aumento de los abandonos y de la mortandad infantil, instrumentalización del cuerpo femenino, vivencia de la sexualidad como un verdadero infierno, etc. ${ }^{12}$ (Petre 1995; Adameşteanu 1998).

Los cambios se hacen notar también en la anatomía de la ciudad -descrita a menudo como un organismo capaz de sentimientos y acciones propiamente humanas-, que es mutilada para adaptarla a los nuevos tiempos, para ofrecer una imagen digna de la nueva era y del «hombre nuevo» que esta pretende erigir. Dej emprende la reconstrucción socialista de la capital (Florea y Gavrila 2007), de acuerdo al modelo soviético, que se plasma tanto en los bloques de viviendas para la clase obrera como en grandes proyectos como Casa Scânteii, la sede del periódico oficial, donde puede apreciarse de forma clara la influencia de emblemáticos edificios moscovitas. Posteriormente, Ceaușescu intensificará las remodelaciones de la urbe, de acuerdo a un plan de sistematización que se saldará con la destrucción de buena parte de su patrimonio arquitectónico, en favor del alzamiento de una ciudad-himno (Fraticelli 2009: 37) que habría de preservar su nombre en la historia ${ }^{13}$. Materializados en el Centro Cívico, coronado por el «mamut» (Cărtărescu 2007: 468) de Casa Poporului, los delirios megalómanos del dictador mutilan el tejido urbano como décadas atrás lo habían hecho las bombas.

\section{Conclusión}

Las visiones de ambos autores contrastan radicalmente, como también la realidad misma, con la que ofrece el discurso oficial, productor activo de mitos destinados a imponer y legitimar el régimen (Zub 1997), que tienen también cabida en estas obras, especialmente en Orbitor. Así, frente a una época comunista gris, tenebrosa que encontramos en las novelas analizadas, y frente a unos personajes a menudo superados por unas circunstancias adversas (que les deparan la muerte, el exilio o, cuando menos, una ardua supervivencia en condiciones denigrantes), la «Edad de Oro» o el «hombre nuevo» propugnados desde el poder

\footnotetext{
tajante rechazo, un año más tarde, a la invasión de Checoslovaquia por parte del Ejército soviético y del resto de países del Tratado de Varsovia, que le valió la aprobación de la mayoría de los rumanos, gracias también a la apelación al sentimiento nacional (Deletant 2006: 176).

${ }^{12}$ En el tomo segundo volumen se describen los denigrantes exámenes ginecológicos a que las trabajadoras eran sometidas en las fábricas.

${ }^{13}$ En este sentido, sigue la estela de otros dirigentes como Kim Il-Sung (Corea del Norte), con quien comparte la misma ambición de comunismo dinástico (Tănase 2009: 153). En sus visitas a Corea o a China, Nicolae Ceaușescu queda fascinado ante los grandiosos espectáculos y la arquitectura monumental dedicados al culto a la personalidad, y tratará de implantarlos también en Rumanía.
} 
evidencian su carácter utópico, falaz. Asimismo, en vista de los abusivos términos impuestos en los acuerdos de paz, la consideración del país como enemigo vencido y el abandono a su suerte por parte de las potencias occidentales, resulta paradójico el rol decisivo en la historia (especialmente en la lucha contra el fascismo y el imperialismo) y la posición central en el mundo (Boia 1997) que el revisionismo historiográfico, importado -si no impuesto- directamente desde Moscú, otorga a Rumanía.

La recreación del conflicto bélico, de sus antecedentes y de sus consecuencias trae consigo, en las obras consideradas, una reflexión sobre la historia rumana más reciente y sobre la concepción que la sociedad tiene de sí misma en relación con ella, que dista enormemente de la versión oficial. En el marco de los primeros años de la ocupación, caracterizados por los atropellos de los soldados soviéticos, a la luz de la indiferencia de Occidente y la institucionalización progresiva de unas medidas supuestamente excepcionales y transitorias, Viziru plantea que tal vez «habría sido mejor que el pueblo rumano no hubiera nacido nunca o que hubiera muerto en la cuna. Somos un pueblo malhadado» (Eliade 2001: 554). El final de Orbitor, si bien culmina con la salvación de los bucarestinos, metonimia de la entera sociedad rumana, condena la capital -la ciudad más triste del mundo (Cărtărescu 2008: 15)-, y con ella al país, a una lluvia de fuego y azufre que la destruye por completo. Pese a los acontecimientos de diciembre de 1989, que acaban con la vida del dictador y ponen fin a decenios de oprobio, el futuro se dibuja, una vez más, tan desdichado como su pasado. Ante las intrigas que rodean a la revolución, recreada alegóricamente, encarnada por una gigante mujer que es violada por quienes van a ostentar el poder, la única esperanza para los rumanos es la de encontrar una tierra mejor.

\section{Referencias bibliográficas:}

AdAMEŞTEANU, Gabriela (1998): «Trecut si viitor. Aspecte ale sexualităţii în epoca Ceauşescu». Revista 22 61. Supliment «Contracepţie? Avort? Planificare familială»: p. I.

BILIUȚă, Ionuț Florin (2007): Between Orthodoxy And The Nation. Traditionalist Definitions Of Romanianness In Interwar Romania. Tesis doctoral: Central European University (Budapest) [en línea]. En: http://www.etd.ceu.hu/2007/biliuta ionut.pdf [12/09/2016].

BoIA, Lucian (1997): «Destinul mare al unei țări mici», en Miturile comunismului românesc. Vol. II, pp. 19-30. Bucarest: Editura Universității din București.

CARMONA FERNÁNDEZ, Fernando (2010): «Maravilloso medieval y modernidad narrativa en La noche de San Juan de Mircea Eliade». Revista de Filología Románica 27: 15-28.

CĂRTĂRESCU, Mircea (2007): Orbitor. Aripa dreaptă. Bucarest: Humanitas.

CĂRTĂRESCU, Mircea (2008): Orbitor. Corpul. Bucarest: Humanitas.

CĂRTĂRESCU, Mircea (2010): Cegador. Madrid: Funambulista.

CERNAT, Paul (2007): «Apocalipsa după Mircea Cărtărescu». Revista 22: 919 [en línea]. En: http://revista22.ro/3948/.html [27/04/2016].

CiOBANU, Vitalie (2002): «Evadarea din “corp" sau al doilea Orbitor de Mircea Cărtărescu». Contrafort 6: 92 [en línea]. En: http://www.contrafort.md/old/2002/92/353.html [27/04/2016].

DeletAnT, Dennis (2006): România sub regimul comunist. Bucarest: Fundația Academia Civică.

EliAde, Mircea (2001): La noche de San Juan. Barcelona: Herder.

EliADE, Mircea (2001b): Diario portugués (1941-1945). Barcelona: Kairós. 
FloreA, Lucian, y GAVRILA, Alina (2007): «Casa Scânteii, la vărsta pensionării». Jurnalul.ro, (18/08/2007) [en línea]. En: http://jurnalul.ro/special-jurnalul/casa-scinteii-lavarsta-pensionarii-100011.html [21/06/2016].

FrATICELli, Barbara (2009): «Bucarest. Encuentros, reencuentros y desencuentros», en Eugenia Popeanga (coord.): Bucarest: luces y sombras, pp. 31-42. Sevilla: Grupo Nacional de Editores.

GARCÍA GARCÍA, Carlos (2007): «Sambô: la melancolía de Eliade», en Llinares, Joan B. (ed.): Mircea Elidade, el profesor y el escritor. Consideraciones en el centenario de su nacimiento, 1907-2007, pp. 51-65. Valencia: Pre-Textos.

GIURESCU, Dinu C. (1999): România în al doilea război mundial (1939-1945). Bucarest: All Educational.

MutTi, Claudio (2005): Mircea Eliade et la Garde de Fer. París: Avatar Éditions.

ONIŞORU, George (1998): România în anii 1944-1948. Transformări economice şi realităţi sociale. Bucarest: Fundaţia Academia Civică.

Petre, Zoe (1995): «Promovarea femeii sau despres destructurarea sexului feminin», en Lucian Boia (coord.): Miturile comunismului românesc. Vol 1, pp. 22-38. Bucarest: Editura Universităţii din Bucureşti.

STEFANESCU, Barbu (2004): "La transición de la dictadura a la democracia. El caso de Rumanía». Pasado y memoria. Revista de historia contemporánea 3: 5-28.

TĂNASE, Stelian (2009): Istoria căderii regimurilor comuniste. Miracol revoluției. Bucarest: Humanitas.

ZuB, Alexandru (1997): «Mituri istoriografice în România ultimei jumătăţi de secol», en Lucian Boia (coord.): Miturile comunismului românesc. Vol.II, pp. 7-18. Bucarest: Editura Universității din București. 